\title{
OmpR positively regulates urease expression to enhance acid survival of Yersinia pseudotuberculosis
}

\begin{abstract}
Correspondence
Shiyun Chen

sychen@wh.iov.cn
\end{abstract}

Received 15 February 2009

Revised 12 May 2009

Accepted 13 May 2009

\author{
Yangbo Hu, ${ }^{1,3}$ Pei Lu, ${ }^{1,3}$ Yao Wang, ${ }^{1}$ Lisha Ding, ${ }^{1,3}$ Steve Atkinson ${ }^{2}$ \\ and Shiyun Chen ${ }^{1}$ \\ ${ }^{1}$ Wuhan Institute of Virology, The Chinese Academy of Sciences, Wuhan 430071, PR China
${ }^{2}$ Institute of Infection, Immunity and Inflammation, Centre for Biomolecular Sciences, University of
Nottingham, Nottingham NG7 2UH, UK
${ }^{3}$ Graduate School of the Chinese Academy of Sciences, Beijing 100049, PR China
}

Yersinia pseudotuberculosis is an enteric bacterium which must overcome the acidic stress in host organs for successful colonization, but how this bacterium survives in acidic conditions remains largely unknown. In the present study, the importance of OmpR in acid survival of $Y$. pseudotuberculosis Yplll was confirmed by the fact that mutation of ompR (strain $\Delta o m p R$ ) greatly reduced cell survival at $\mathrm{pH} 4.5$ or lower. To characterize the regulatory role of $\mathrm{OmpR}$ in this acid survival process, proteomic analysis was carried out to compare $\mathrm{Yplll}$ at $\mathrm{pH} 7.0$ and $\mathrm{pH} 4.5$ with $\Delta o m p R$ at $\mathrm{pH} 7.0$, and urease components were revealed to be the main targets for OmpR regulation. Addition of urea to the culture medium also enhanced acid survival of Yplll but not $\triangle o m p R$ and urease activity was significantly induced by acid in Yplll but not in $\Delta o m p R$. Each of the seven components of the Yplll urease gene cluster was fused to a lacZ reporter and their expression was dramatically decreased in a $\triangle o m p R$ background; this supports the notion that OmpR positively regulates urease expression. Furthermore, gel shift analysis revealed that OmpR binds to the deduced promoter regions of three polycistronic transcriptional units (ure $A B C$, ure $E F$ and $u r e G D$ ) in the urease cluster, suggesting that the regulation of OmpR to urease components is direct. Taken together, these data strongly suggest that $\mathrm{OmpR}$ activates urease expression to enhance acid survival in $Y$. pseudotuberculosis.

\section{INTRODUCTION}

The acidity of the stomach is a primary barrier which all food-borne microbial pathogens must overcome. Consequently, many food-borne pathogens have developed survival systems that protect against acidic conditions (Bearson et al., 1997; Lin et al., 1995). There are two types of acid survival systems currently described. The acid tolerance response (ATR), usually induced by sublethal environmental acid $\mathrm{pH}$ ( $\mathrm{pH} 5.5$ to 4.5 ), is a moderately effective system that protects bacteria such as Salmonella enterica at $\mathrm{pH} 3.0$ or above (Boot et al., 2002). However, some bacteria have more effective survival mechanisms known as acid resistance (AR) systems that will protect at $\mathrm{pH} 2.5$ or below. AR systems have been extensively studied in Helicobacter pylori, Salmonella typhimurium and Escherichia coli (Bearson et al., 1997; Lin et al., 1995; Pflock et al., 2006b). E. coli possesses at least three complex cellular systems involved in the regulation of cytoplasmic

Abbreviations: AR, acid resistance; ATR, acid tolerance response; YLB, Yersinia-Luria-Bertani.

Two supplementary tables and two supplementary figures are available with the online version of this paper.
pH (Foster, 2004; Richard \& Foster, 2003), with RpoS (also known as $\sigma^{\mathrm{S}}$ ) and CRP (cAMP receptor protein), GadABC and AdiAC (amino acid decarboxylases and cognate antiporters) playing key roles in these systems. In addition, many other genes which express metabolic enzymes, periplasmic proteins and regulators involved in AR in $E$. coli have also been examined by microarray and proteomic 2D-gel analyses (Blankenhorn et al., 1999; Tucker et al., 2002). Recently, the Lon protease, endoRNase RNase E and chaperone Hsp31 have been shown to be important in controlling AR systems in E. coli (Heuveling et al., 2008; Mujacic \& Baneyx, 2007; Takada et al., 2007), and the roles of AraC-family regulators GadX and GadW and the multidrug resistance regulator MarA in AR systems have also been investigated (Ruiz et al., 2008; Sayed et al., 2007; Tramonti et al., 2006). Nevertheless, despite advances in unravelling some of the regulatory networks involved in AR systems (Foster, 2004; Masuda \& Church, 2003), it remains unclear how these factors function together to promote cell survival in low $\mathrm{pH}$ conditions.

In addition to resistance to extremely acidic $\mathrm{pH}$, foodborne pathogens also develop ATR systems to survive 
weakly acidic environments in acidic foods, animal feeds, food-processing treatments, macrophage phagolysosomes and intestines (Castillo et al., 1999; Leyer et al., 1995; Young et al., 1996). The ATR has been extensively studied in S. enterica serovar Typhimurium, revealing a number of acid-shock proteins which are required in this process (Bang et al., 2000; Lee et al., 1994). Urease, a nickel metalloenzyme catalysing the hydrolysis of urea to form carbon dioxide and ammonia, was shown to enhance acid tolerance in Yersinia enterocolitica (De Koning-Ward \& Robins-Browne, 1995; Young et al., 1996) and the AR in $H$. pylori (Marshall et al., 1990). It has been proposed that urease hydrolyses urea in animal organs and produces sufficient ammonia to raise the $\mathrm{pH}$ to levels at which the bacteria remain viable (Stingl \& De Reuse, 2005).

Y. pseudotuberculosis, a Gram-negative gastrointestinal pathogenic bacterium, causes self-limiting gastroenteritis and mesenteric lymphadenitis. Transmission between animals and humans is normally through the ingestion of contaminated food or faecal material (Nagano et al., 1997). Survival in acidic environments is important for infection, but the $Y$. pseudotuberculosis acid response is not well understood. Although several homologues of genes such as $r p o S$, crp and ure $A B C$, which are important for acid survival in other pathogenic bacteria (Castanie-Cornet et al., 1999; De KoningWard \& Robins-Browne, 1995), are present in Y. pseudotuberculosis, it remains unclear which of these genes are involved in acid survival in this bacterium. PhoP (regulator of the PhoP-PhoQ system) has been shown to play a key role in survival in macrophages in Y. pseudotuberculosis (Grabenstein et al., 2004) and the two-component system regulon assay also showed that mutations of key regulator genes such as ompR (regulator of the EnvZ-OmpR system), phoP and pmrA (regulator of the PmrA-PmrB system) altered its acid survival (Flamez et al., 2008). Among these regulators, OmpR is the most important two-component regulator in the acid response since mutation of $o m p R$ decreased the acid survival of $Y$. pseudotuberculosis 32777 compared to other mutants, such as phoP and pmrA mutants (Flamez et al., 2008). Since the details of the regulatory role of $\mathrm{OmpR}$ in this process are unclear, we constructed an ompR mutant in $Y$. pseudotuberculosis to investigate the role of OmpR in acid survival. We then sought to investigate by proteomic analysis how OmpR regulates other proteins to increase acid survival in $Y$. pseudotuberculosis and revealed that urease components are the main targets for OmpR regulation in acid survival. Transcriptional analysis and gel retardation assays indicate that the urease locus is divided into three transcriptional units and that OmpR directly binds to the promoter regions upstream of each of these transcriptional units. We propose that this binding activates urease expression and enhances the acid survival response of $Y$. pseudotuberculosis.

\section{METHODS}

Bacterial strains, plasmids and culture conditions. The bacterial strains and plasmids used in this study are listed in Table 1. E. coli cultures were routinely grown in Luria-Bertani (LB) medium at $37{ }^{\circ} \mathrm{C}$. Y. pseudotuberculosis (YpIII) was grown in Yersinia-LuriaBertani (YLB) broth or on YLB agar $\left(\mathrm{YLB}_{\mathrm{A}}\right)$ plates (Lennox, 1955) at $28{ }^{\circ} \mathrm{C}$ or $37^{\circ} \mathrm{C}$ with the appropriate antibiotics where required.

Acid survival assays. Stationary-phase overnight cultures of YpIII, the ompR mutant (strain $\Delta o m p R$ ) and its complemented strain $\left(\Delta o m p R\right.$-com) grown in YLB medium at $\mathrm{pH} 7.0$ were diluted $\left(10^{6}\right.$ c.f.u. $\mathrm{ml}^{-1}$ ) into fresh YLB at different $\mathrm{pH}$ values ( $\mathrm{pH}$ 5.5-3.0) and incubated at $37{ }^{\circ} \mathrm{C}$ for $2 \mathrm{~h}$. The cultures were serially diluted and plated onto $\mathrm{YLB}_{\mathrm{A}}$, and colonies were counted after $20 \mathrm{~h}$ growth at $37{ }^{\circ} \mathrm{C}$. Percentage survival was calculated as follows: [(c.f.u. $\mathrm{ml}^{-1}$ after challenge at different $\mathrm{pH}$ values)/(c.f.u. $\mathrm{ml}^{-1}$ at $\mathrm{pH} 7.0$ before acid challenge) $] \times 100$.

2D-gel analysis and protein identification. Overnight cultures (stationary phase) of YpIII or $\Delta o m p R$ grown at $\mathrm{pH} 7.0$ at $28{ }^{\circ} \mathrm{C}$ were shifted to $37{ }^{\circ} \mathrm{C}$ for a further $2 \mathrm{~h}$ incubation; or for acid challenge, YpIII cultures diluted into YLB at pH 4.5 were incubated at $37{ }^{\circ} \mathrm{C}$ for a further $2 \mathrm{~h}$. These cells were then centrifuged at $5000 \mathrm{~g}$ for $5 \mathrm{~min}$ and washed in $10 \mathrm{mM}$ Tris (pH 7.0) and $0.4 \mathrm{M}$ sucrose. After centrifugation at $5000 \mathrm{~g}$ at $4{ }^{\circ} \mathrm{C}$ for $5 \mathrm{~min}$, cell pellets were resuspended in lysis buffer containing $8 \mathrm{M}$ urea, $2 \mathrm{M}$ thiourea, $4 \%$ (w/v) 3-[(3-cholamidopropyl)dimethylammonio]propanesulfonate, $1 \%(\mathrm{w} / \mathrm{v})$ dithiothreitol, $0.8 \% \quad(\mathrm{v} / \mathrm{v})$ ampholytes ( $\mathrm{pH} 4.0-7.0$, Amersham), $1 \mathrm{mM}$ phenylmethanesulfonyl fluoride, $350 \mathrm{mM}$ Tris base and $5 \mathrm{mM}$ EDTA. Cells were lysed by sonication and centrifuged at $10000 \mathrm{~g}$ at $4{ }^{\circ} \mathrm{C}$ for $10 \mathrm{~min}$ to remove unbroken cells. The total protein concentration in the supernatant was determined by the method of Bradford (1976), using BSA as a standard. For 2D-gel analysis a Multiphor II electrophoresis unit (Amersham) was used in the first-dimension IEF, and a Bio-Rad Protean II Xi unit (Bio-Rad) in the second-dimension electrophoresis. Each sample was prepared and analysed in triplicate. For comparison of spot densities between different strains and growth conditions, gels were stained with colloidal CBB G-250 and scanned with a PowerLook 1000 (UMAX Technologies). PDQuest version 7.3.0 (Bio-Rad) was used for image analysis. Proteins with densities which increased or decreased $\geqslant 2$ fold in all three experiments were excised and digested with trypsin, and identified by MALDI-TOF MS.

Mutation and complementation of ompR. To construct the $\Delta o m p R$ mutant, two DNA fragments (1006 bp and $996 \mathrm{bp}$ ) up- and downstream of the $o m p R$ gene, which omitted 453 bp downstream from the ATG initiation codon in $\operatorname{ompR}$, were amplified using two pairs of primers, PompR-up-SF/PompR-up-XR and PompR-down$\mathrm{XF} /$ PompR-down-BR (primer sequences are listed in Supplementary Table S1, available with the online version of this paper). To construct the $\Delta$ ure $C$ mutant, two fragments (509 bp and $565 \mathrm{bp}$ ) up- and downstream of the ureC gene, which omitted 510 bp downstream from the ATG initiation codon in ure $C$, were amplified using two pairs of primers, PureC-up-SF/PureC-up-ER and PureC-down-EF/ PureC-down-BR (Table S1). For each mutant the PCR products were digested with the appropriate restriction enzymes and inserted into similarly digested pDM4 to obtain pDM4-ompRm and pDM4-ureCm, and subsequently transformed into E. coli $\operatorname{S17-1}(\lambda-p i r)$. Transconjugation was performed as described by Atkinson et al. (1999) to obtain strains $\Delta o m p R$ and $\Delta u r e C$, respectively.

To complement the ompR mutation, primers P25-SSF and P25A-R (Table S1) were used to amplify a fragment from the multiple cloning site to the p15A replicon of pKT25 (Karimova et al., 1998), and primers PACYC-F and PACYC-p-SR were used to amplify a fragment from the p15A replicon to the initiation codon of the chloramphenicol resistance gene from pACYC184 (Rose, 1988). Overlap PCR was carried out using primers P25-SSF and PACYC-p-SR to obtain the full-length DNA fragment containing the multiple cloning site, p15A 
Table 1. Strains and plasmids used in this study

\begin{tabular}{|c|c|c|}
\hline Strain or plasmid & Relevant characteristics ${ }^{\star}$ & Reference \\
\hline \multicolumn{3}{|l|}{ E. coli } \\
\hline S17-1( $\lambda$-pir $)$ & $\lambda$-pir lysogen of S17-1, thi pro hsdR $h s d M^{+}$recA RP4 2-Tc::Mu-Km:: Tn7 & Simon et al. (1983) \\
\hline BL21(DE3) & Host for expression vector $\mathrm{pET} 32 \mathrm{a}$ & Novagen \\
\hline \multicolumn{3}{|c|}{ Y. pseudotuberculosis } \\
\hline YpIII & Wild-type $Y$. pseudotuberculosis $\mathrm{pIB1}, \mathrm{Nal}^{\mathrm{r}}$ & Rosqvist et al. (1988) \\
\hline$\Delta o m p R$ & $o m p R$ gene deleted in YpIII, $\mathrm{Nal}^{\mathrm{r}}$ & This study \\
\hline$\Delta o m p R-c o m$ & $\Delta o m p R$ carrying plasmid $\mathrm{pKT}-o m p R, \mathrm{Nal}^{\mathrm{r}} \mathrm{Kan}^{\mathrm{r}}$ & This study \\
\hline sureC & ureC gene deleted in YpIII, $\mathrm{Nal}^{\mathrm{r}}$ & This study \\
\hline \multicolumn{3}{|l|}{ Plasmids } \\
\hline pKT100 & Cloning vector, p15A replicon, $\mathrm{Kan}^{\mathrm{r}}$ & This study \\
\hline pKT-ompR & $\operatorname{omp} R$ under promoter of chloramphenicol resistance gene in plasmid $\mathrm{pKT} 100, \mathrm{Kan}^{\mathrm{r}}$ & This study \\
\hline pET32a & Expression vector for His-bind fusion proteins, $A_{m p}{ }^{r}$ & Novagen \\
\hline pET32a-OmpR & pET32a carrying ompR coding region, $A m p^{r}$ & This study \\
\hline pDM4 & Suicide vector, mobRK2 oriR6K (pir requiring) sacBR of Bacillus subtilis, $\mathrm{Cm}^{\mathrm{r}}$ & O’Toole et al. (1996) \\
\hline pDM4-ompRm & pDM4 carrying two DNA fragments up- and downstream of $o m p R, \mathrm{Cm}^{\mathrm{r}}$ & This study \\
\hline pDM4-ureCm & pDM4 carrying two DNA fragments up- and downstream of $u r e C, \mathrm{Cm}^{\mathrm{r}}$ & This study \\
\hline pDM4-lacZ & pDM4 carrying lac $Z$, used for $l a c Z$ gene fusion construction, $\mathrm{Cm}^{\mathrm{r}}$ & This study \\
\hline pDM4-1131Z & 309 bp DNA fragment before ureA stop codon inserted into pDM4-lacZ, $\mathrm{Cm}^{\mathrm{r}}$ & This study \\
\hline pDM4-1132Z & 483 bp DNA fragment before $u r e B$ stop codon inserted into pDM4-lac $Z, \mathrm{Cm}^{\mathrm{r}}$ & This study \\
\hline pDM4-1133Z & 461 bp DNA fragment before ureC stop codon inserted into $\mathrm{pDM} 4-\mathrm{lac} Z, \mathrm{Cm}^{\mathrm{r}}$ & This study \\
\hline pDM4-1134Z & 508 bp DNA fragment before ureE stop codon inserted into pDM4-lacZ, $\mathrm{Cm}^{\mathrm{r}}$ & This study \\
\hline pDM4-1135Z & 532 bp DNA fragment before $u r e F$ stop codon inserted into pDM4-lacZ, $\mathrm{Cm}^{\mathrm{r}}$ & This study \\
\hline pDM4-1136Z & 526 bp DNA fragment before $u r e G$ stop codon inserted into pDM4-lacZ, $\mathrm{Cm}^{\mathrm{r}}$ & This study \\
\hline pDM4-1137Z & 469 bp DNA fragment before ureD stop codon inserted into pDM4-lacZ, $\mathrm{Cm}^{\mathrm{r}}$ & This study \\
\hline
\end{tabular}

${ }^{\star} \mathrm{Nal}^{\mathrm{r}}, \mathrm{Cm}^{\mathrm{r}}, \mathrm{Kan}^{\mathrm{r}}$ and $\mathrm{Amp}^{\mathrm{r}}$ represent resistance to naladixic acid, chloramphenicol, kanamycin and ampicillin at 15, 30, 50 and 100 $\mu \mathrm{g} \mathrm{ml}^{-1}$, respectively.

replicon, kanamycin resistance gene and the promoter region of the chloramphenicol resistance gene, which was digested with SphI and ligated to obtain pKT100. ompR was amplified using primers PompRo-SF and PompRo-SR and inserted into pKT100 to obtain pKT-ompR, which was then introduced into $\Delta o m p R$ to obtain the complemented strain $(\Delta o m p R-c o m)$.

Urease activity assay. Urease activity was quantified by determining the rate of ammonia produced from the hydrolysis of urea as described by Young et al. (1996). Assays were done in duplicate for at least two time points to determine the rate of ammonia produced per minute. The protein concentration was determined by the method of Bradford (1976), using BSA as a standard. Urease activity was expressed as micromoles ammonia produced per min per mg protein.

Construction of lacZ fusions. To construct plasmids containing the genes of the ureA-D cluster fused to lac $Z$, each primer pair was designed such that the reverse primer incorporated the $3^{\prime}$-end of the gene (omitting the stop codon, which allows for the continued translation of lacZ), and the forward primer of each gene was designed 309-532 bp upstream of the stop codon (all primers are listed in Table S1). Each PCR product (the length of each DNA fragment is listed in Table 1) was inserted between the SalI and SpeI sites of pDM4-lac $Z$ to generate a series of plasmids named pDM4$1131 \mathrm{Z}$ to pDM4-1137Z (Table 1) before being transformed into E. coli S17-1( $\lambda$-pir). Homologous recombination was carried out as described by Atkinson et al. (1999), with the successful reporter insertions being selected on Yersinia selective agar (Oxoid) containing nalidixic acid and chloramphenicol.
$\boldsymbol{\beta}$-Galactosidase assay. YpIII or $\Delta o m p R$ transformants carrying plasmids pDM4-1131Z to pDM4-1137Z (Table 1) were cultured overnight at $28{ }^{\circ} \mathrm{C}$ in YLB and then transferred into fresh acidic YLB at the appropriate $\mathrm{pH}$. After incubation at $37^{\circ} \mathrm{C}$ for $2 \mathrm{~h}$, cells were collected and transferred into YLB ( $\mathrm{pH} 7.0)$. $\beta$-Galactosidase activity was determined as described by Miller (1992) and calculated using the formula $\left[1000 \times\left(A_{420}-1.75 A_{550}\right)\right] /\left[\mathrm{OD}_{600} \times\right.$ culture volume $(\mathrm{ml}) \times$ reaction time $(\mathrm{min})]$.

Transcription unit analysis. YpIII grown to stationary phase was transferred into fresh YLB at $\mathrm{pH} 4.5$ for $2 \mathrm{~h}$ at $37^{\circ} \mathrm{C}$. Total RNA was isolated using the E.Z.N.A Bacterial RNA kit (Omega Bio-Tek). The cDNA was synthesized with the reverse primers P1133R, P1135R, P1136R and P1137R (Table S1) following RNase-free DNase I (Promega) treatment. Primers P1133F, P1132F and P1131F were paired with P1133R to test the transcription of ureABC. Similar primer pairs were used in $u r e E F$ and ureGD transcription. Total RNA and genomic DNA were used as templates for negative and positive controls, respectively.

OmpR expression and purification. The coding region of $o m p R$ was amplified using primers PompR-BF and PompR-HR (Table S1), digested with BamHI and HindIII and inserted into similarly digested pET32a (Novagen) to obtain pET32a-OmpR. Following transformation into E. coli BL21(DE3) OmpR expression was induced by adding $1 \mathrm{mM}$ IPTG to cultures at an $\mathrm{OD}_{600}$ of 0.6 and incubating at $28^{\circ} \mathrm{C}$ for $4 \mathrm{~h}$. Ni-NTA resin (Novagen) was used to purify $\mathrm{His}_{6}-\mathrm{OmpR}$ as described by the manufacturer.

Gel-retardation assay. To investigate whether OmpR would interact with promoter regions derived from the urease cluster, a 
modification of the method described by Huang et al. (2006) was performed. DNA fragments named Fa (251 bp), Fe (280 bp), Fg (227 bp) and Fd (248 bp) (see Fig. 4a) were amplified from the urease cluster using primer pairs Pfa-F/Pfa-R, Pfe-F/Pfe-R, Pfg-F/Pfg-R and Pfd-F/Pfd-R (Table S1). Samples (200 ng) of DNA were incubated with various amounts of purified OmpR protein in $20 \mu$ l binding buffer containing $20 \mathrm{mM}$ Tris/ $\mathrm{HCl}$ ( $\mathrm{pH} 7.4$ ), $4 \mathrm{mM} \mathrm{MgCl}_{2}, 100 \mathrm{mM}$ $\mathrm{NaCl}, 1 \mathrm{mM}$ dithiothreitol, $10 \%$ glycerol and 100 ng BSA. For OmpR phosphorylation, $100 \mathrm{mM}$ acetyl phosphate (Sigma) was added to the reaction mixture. OmpR phosphorylation and probe binding were performed at $37^{\circ} \mathrm{C}$ for $1 \mathrm{~h}$. The samples were then loaded onto a $6.5 \%$ native polyacrylamide gel. Electrophoresis was performed in $0.5 \times$ TBE buffer containing $45 \mathrm{mM}$ Tris, $45 \mathrm{mM}$ boric acid and $1 \mathrm{mM}$ EDTA on ice for $4 \mathrm{~h}$. The gel was stained with ethidium bromide for $20 \mathrm{~min}$ and scanned using a Syngene GeneGenius gel documentation system.

\section{RESULTS}

\section{OmpR is essential for survival of Yplll at acidic pH}

After incubation at $\mathrm{pH} 4.5$ for $2 \mathrm{~h}$, the survival of the YpIII parent and $\Delta o m p R$-com strains was $62.3 \%$ and $73.6 \%$, respectively, but only $4.5 \%$ of the $\Delta o m p R$ cells remained viable (Fig. 1). Survival of YpIII and $\Delta o m p R$-com at $\mathrm{pH} 4.0$ was also much higher than that of $\Delta o m p R$. None of the strains were able to tolerate $\mathrm{pH}$ below 4.0, with little or no survival once challenged (Fig. 1). This result underlines the importance of OmpR in acid survival of YpIII at $\mathrm{pH}$ 4.0-5.0.

\section{Identification of OmpR-regulated proteins related to acid survival by 2D-gels}

Since OmpR appears to be important for acid survival of YpIII, proteomic 2D-gel analysis was performed to identify OmpR-regulated proteins which might be involved in this response. Global proteins isolated from YpIII grown at $\mathrm{pH} 4.5$ and $\mathrm{pH} 7.0$ and $\Delta o m p R$ at $\mathrm{pH} 7.0$ were compared to find proteins regulated by both the acid response and OmpR. 2D-gel analysis revealed that in the YpIII parent 21 spots showed a $>2$-fold change at $\mathrm{pH} 4.5$ compared to

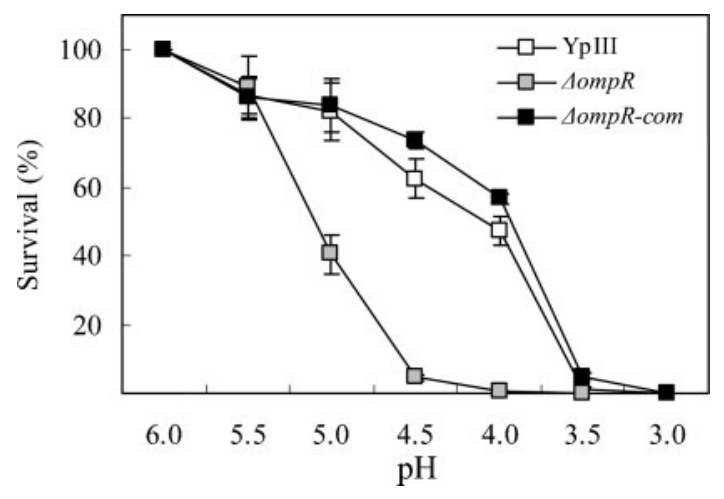

Fig. 1. Survival of Yplll, $\Delta o m p R$ and its complemented strain $(\Delta o m p R$-com) at different $\mathrm{pH}$ values.
$\mathrm{pH}$ 7.0. Six of these spots were found to be OmpRregulated since their expression was increased at $\mathrm{pH} 4.5$ compared to $\mathrm{pH} 7.0$ in YPIII but decreased at $\mathrm{pH} 7.0$ in $\triangle o m p R$ (Table S2). These six proteins were examined by MALDI-TOF MS; spots 20 and 21 were identified as the $\alpha$ subunit of urease (UreC) and spot 6 was identified as the urease accessory protein, UreG (Fig. 2). Both UreC and UreG have been reported to participate in acid tolerance in $Y$. enterocolitica (De Koning-Ward \& Robins-Browne, 1995), indicating that urease is a major candidate for OmpR-regulated proteins related to acid survival in YpIII.

\section{OmpR controls urease activity}

To test if urease is important for OmpR-controlled acid survival, the effects of urea on cell survival of YpIII and $\Delta o m p R$ were tested. As shown in Fig. 3(a), increasing the concentration of urea enhanced the survival of the YpIII parent and $\Delta o m p R$-com at $\mathrm{pH} 4.5$ but failed to increase the survival of $\Delta o m p R$ and $\Delta u r e C$ (used as a control in this assay), even in the presence of $20 \mathrm{mM}$ urea. These data are consistent with the results presented in Fig. 2, which show that $\Delta o m p R$ poorly expresses urease components. Similar results were also obtained at $\mathrm{pH} 5.0$ and $\mathrm{pH} 4.0$ (data not shown). These results suggest that urease is important for OmpR-controlled acid survival in YpIII.

A quantitative urease activity assay was also performed to compare urease activities between YpIII, $\Delta o m p R$ and $\Delta o m p R$-com. Urease activities increased in YpIII and $\Delta o m p R$-com with decreasing $\mathrm{pH}$, but there was no obvious increase in urease activity in $\triangle o m p R$ or $\Delta u r e C$ (Fig. $3 \mathrm{~b}$ ). Moreover, $\Delta o m p R$ showed lower urease activity than YpIII at each $\mathrm{pH}$, and the differences were more pronounced at acidic $\mathrm{pH}$ (Fig. 3b). Taken together, these two results demonstrate that OmpR positively controls urease activity in a $\mathrm{pH}$-dependent manner.

\section{OmpR positively regulates urease gene expression}

The chromosomally located ure locus of YpIII, which is responsible for the production of urease components, was analysed; this revealed that the genes encoding three urease subunits $(\alpha, \beta$ and $\gamma)$ and four accessory proteins (UreDEFG) are arranged as reported for $Y$. enterocolitica (De Koning-Ward et al., 1994) (Fig. 4a). In order to test which of these genes were regulated by OmpR, each was fused to lac $Z$ and $\beta$-galactosidase activity was measured at $\mathrm{pH}$ 7.0, 5.5, 5.0 and 4.5 in YpIII and $\Delta o m p R$. Fig. 4(b) shows that the expression of ureA-ureD decreased in the ompR mutant compared to the YPIII parent. This result supports our 2D-gel data showing that the expression of UreC and UreG decreases in $\Delta o m p R$ (Fig. 2). In addition, an increase in the expression of all of the urease components at acidic $\mathrm{pH}$ was observed in YpIII but not in $\Delta o m p R$, which indicates that OmpR plays a key role in the acid-induction of urease components (Fig. $4 \mathrm{~b}$ ). 


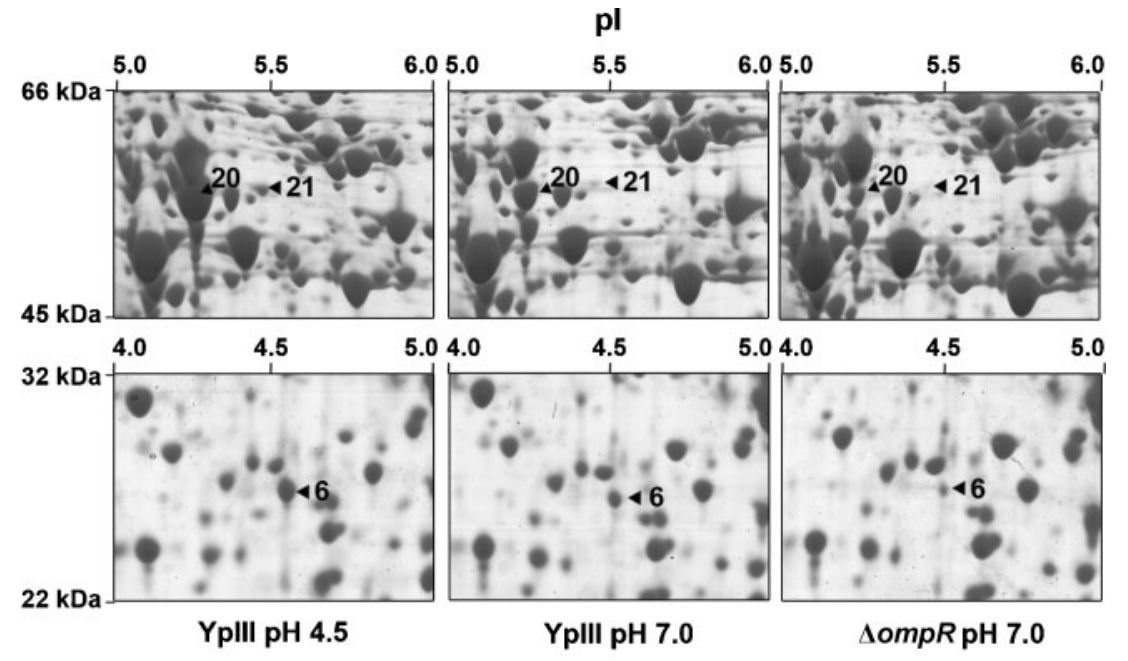

Fig. 2. Proteomic comparison of Yplll at $\mathrm{pH} 4.5$ and $\mathrm{pH} 7.0$ with $\Delta o m p R$ at $\mathrm{pH} 7.0$ using 2D-gel analysis. Arrows indicate proteins whose expression was increased at $\mathrm{pH} 4.5$ compared to $\mathrm{pH} 7.0$ in Yplll but decreased at $\mathrm{pH} 7.0$ in $\Delta o m p R$. (a)

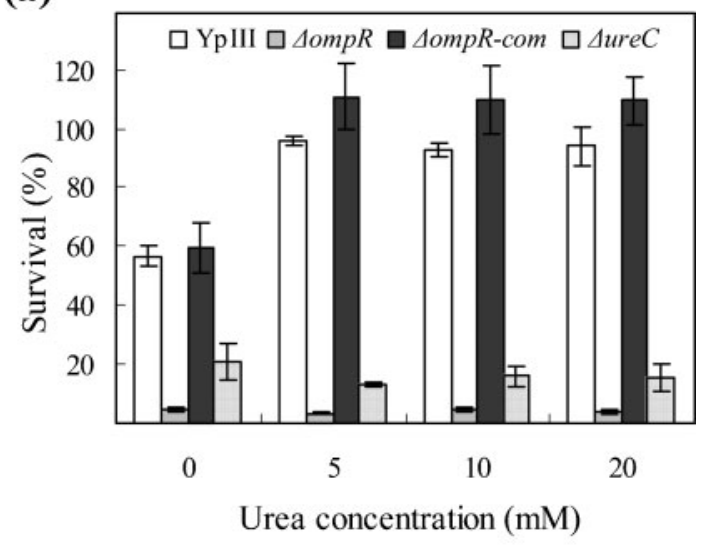

(b)

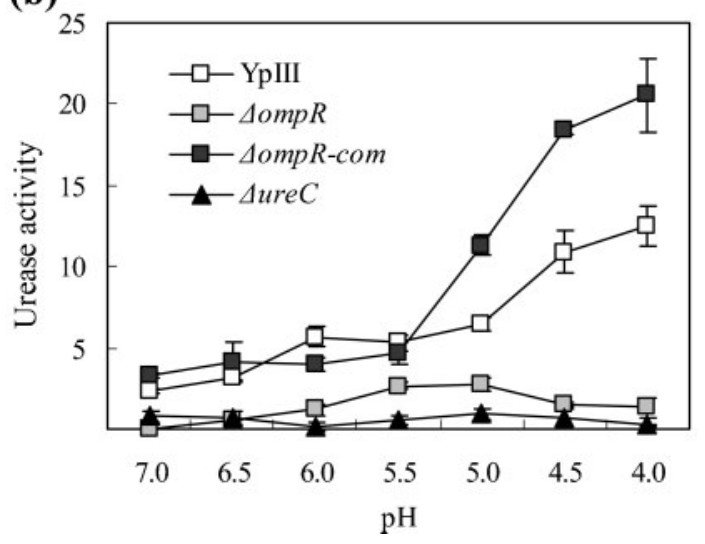

Fig. 3. Effect of urea on (a) acid survival and (b) urease activity of Yplll, $\Delta o m p R, \Delta o m p R$-com and $\Delta u r e C$ at different $\mathrm{pH}$ values.

\section{OmpR directly binds to the urease cluster}

To determine whether OmpR directly regulates urease expression, gel-retardation assays were undertaken to analyse the interaction of $\mathrm{OmpR}$ with the promoter regions of components of the urease cluster. Since the transcriptional organization of the urease cluster is unclear in YPIII it was first necessary to identify the promoters in this region. Inverse PCR was applied to confirm which of these genes were in the same transcriptional unit. RNA was first amplified using the seven primer pairs designed to the urease genes to confirm that there was no genomic DNA contamination after DNase digestion (Fig. 5b, lane R, as an example and data not shown) and then cDNA was synthesized as described in Methods. Fig. 5(b) reveals that ure $A B C$ were amplified together from the same cDNA (Fig. 5 b, lane 3 ), indicating that they are in same transcriptional unit. ureEF were also amplified together, indicating that they also form a distinct transcriptional unit (Fig. 5b, lane 5 ) as do ureGD (Fig. 5b, lane 10). Because ureCEF could not be amplified from the same cDNA we propose that $u r e E F$ and ure $A B C$ are transcribed separately (Fig. 5b, lane 6). Similarly, ureEF and ureGD are two independent transcription units because ureFG could not be amplified from the same cDNA (Fig. 5b, lane 8). Taken together, these results indicate that there are three transcriptional units (ure $A B C$, ureEF and ureGD) in the urease cluster with a promoter region located upstream of each unit in YpIII. In accordance with this cluster organization, the three transcriptional units are separated by two intergenic regions (296 bp and $127 \mathrm{bp}$ ) in the YpIII chromosome (Fig. 4a). In gel-retardation experiments, three different DNA fragments of 251, 227 and $280 \mathrm{bp}$ upstream of ureA, ure $E$ and ure $G$ named Fa, Fe, Fg respectively (Fig. 4a) were amplified and used as the targets for OmpR binding in gel retardation assays. A fourth fragment of $248 \mathrm{bp}$ (Fd; Fig. 4a), which is located upstream of ureD, was used as a control. OmpR interacts with $\mathrm{Fa}, \mathrm{Fe}$ and $\mathrm{Fg}$ since the bound fragments (B) are clearly visible (Fig. 6a, b, c) while 
(a)

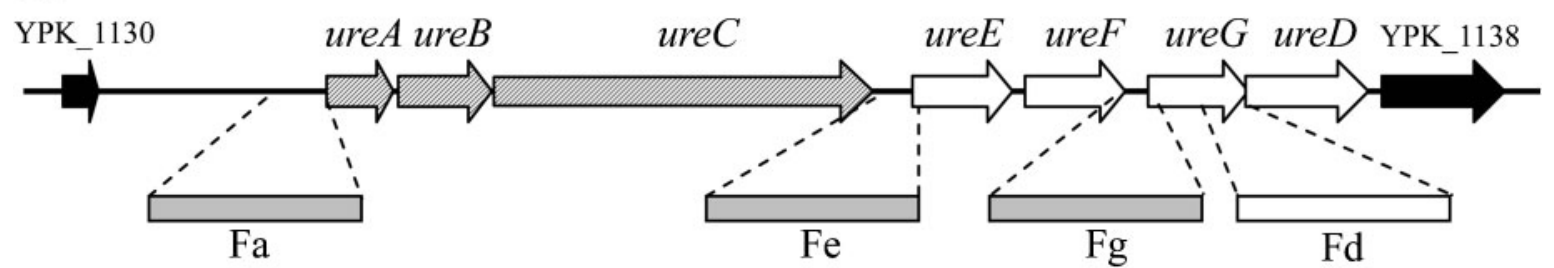

(b)

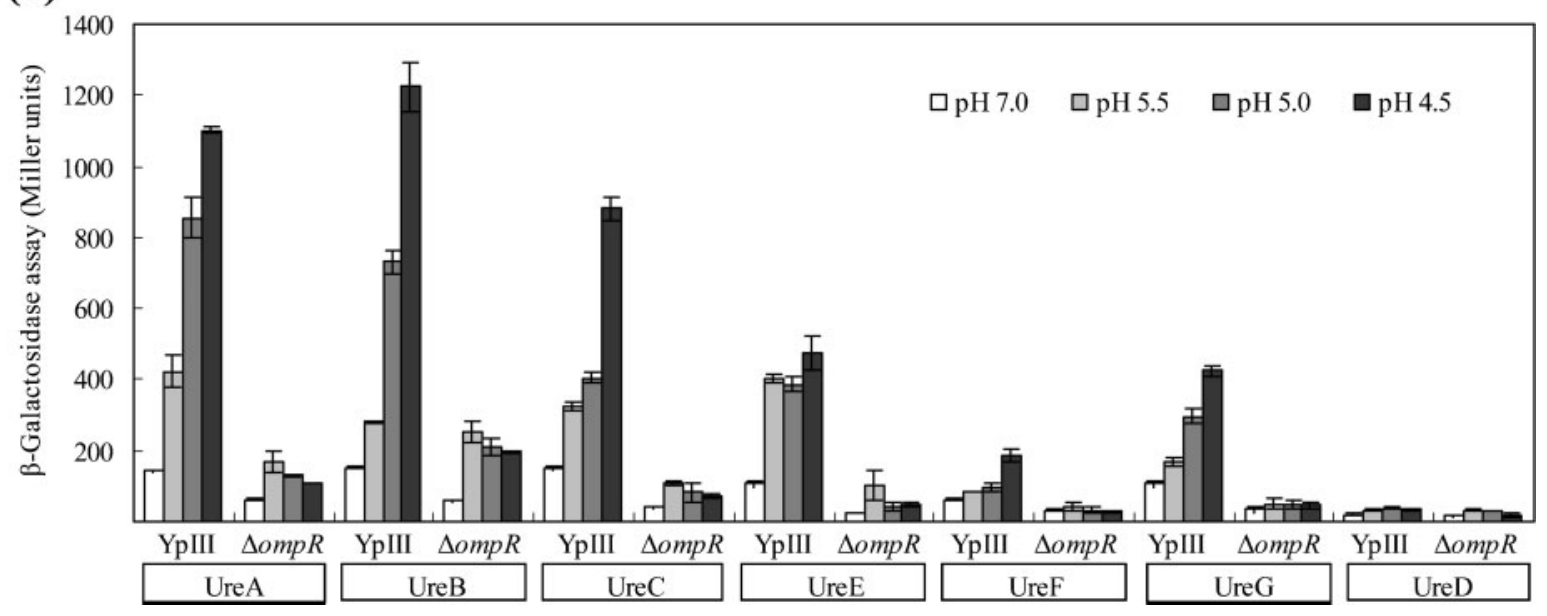

Fig. 4. (a) Organization of the genes constituting the urease locus of Yplll. Fragments upstream of ure $A$, ureE, ureG and ureD ( $\mathrm{Fa}, \mathrm{Fe}, \mathrm{Fg}$ and $\mathrm{Fd}$ ) were amplified by PCR and used in OmpR binding activity assays. (b) Expression of the urease cluster genes in Yplll and $\Delta o m p R$ at different $\mathrm{pH}$ values.

the control DNA fragment Fd showed no interaction with OmpR (Fig. 6d). This result helps to confirm that OmpR binds directly to the promoter regions in the urease cluster to activate the expression of urease components.

\section{DISCUSSION}

Enteric pathogens must pass through the stomach at $\mathrm{pH}<3.0$ for up to $2 \mathrm{~h}$ before colonizing the intestinal tract (Giannella et al., 1972). In the present study, over $50 \%$ of (a)

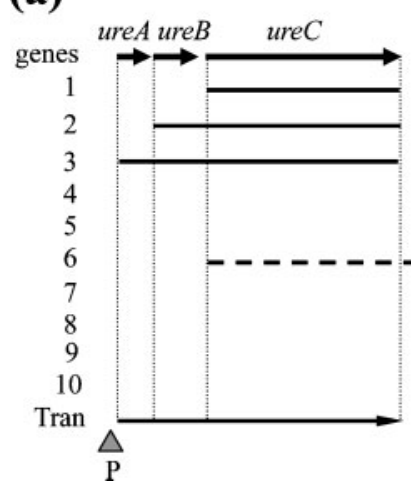

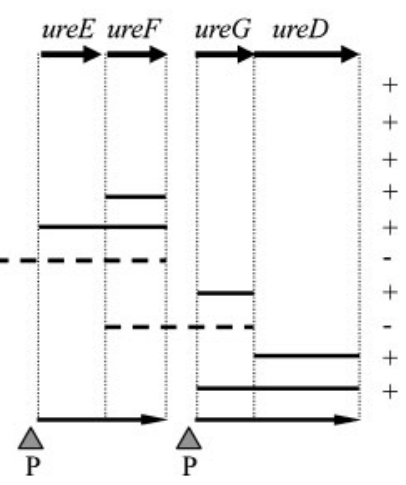

(b)

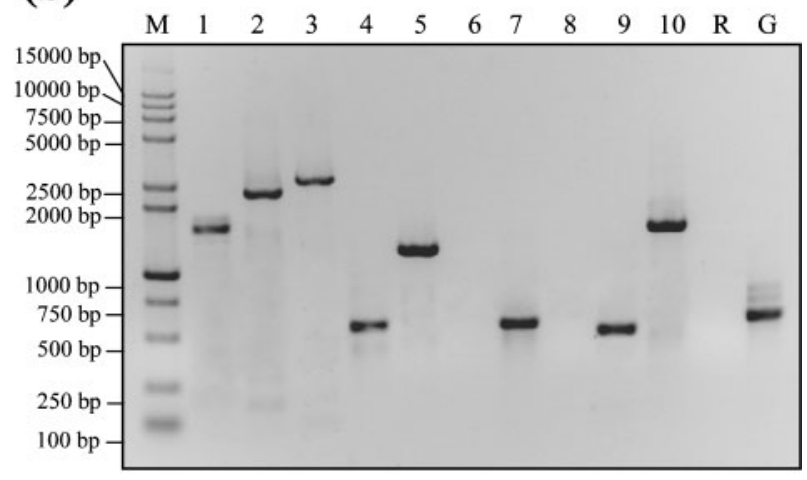

Fig. 5. (a) Transcriptional unit analysis of the urease cluster. DNA fragments that can be amplified from one cDNA are shown as solid lines and ' + ' and fragments that cannot be amplified are showed as dashed lines and ' - '. The transcriptional units identified are labelled 'Tran' and deduced promoters are indicated as 'P'. (b) Inverse PCR. Lanes 1-10 correspond to the row numbers in (a). Lanes R and G are PCR products using RNA and genomic DNA isolated from Yplll as templates for primers $\mathrm{P} 1136 \mathrm{~F}$ and $\mathrm{P} 1136 \mathrm{R}$, respectively. Lane $\mathrm{M}$, size standards. 
(a)

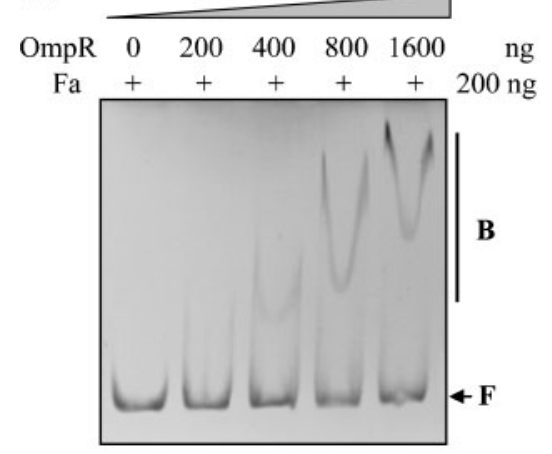

(c)

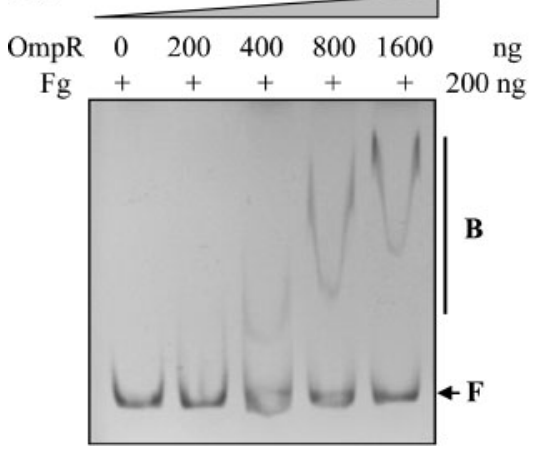

(b)

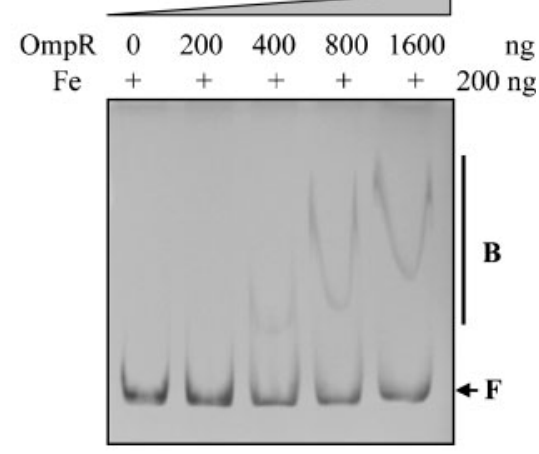

(d)

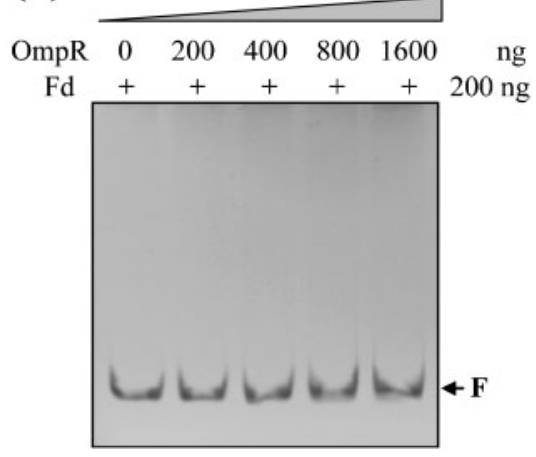

Fig. 6. Interaction of $\mathrm{OmpR}$ with the promoter regions in the urease cluster studied by gelretardation assays. The promoter regions of $\operatorname{ure} A B C(\mathrm{Fa})(\mathrm{a})$, ureEF $(\mathrm{Fe})(\mathrm{b})$ and ure $G D$ $(\mathrm{Fg})(\mathrm{c})$ were incubated with different amounts of OmpR protein (shown at the top of each lane). The positions of bound (B) and free (F) fragments are shown to the right of each panel. A 248 bp DNA fragment upstream of ureD named Fd was amplified and used as a negative control (d). the YpIII parent challenged at $\mathrm{pH} 4.5$ for $2 \mathrm{~h}$ survived but this decreased to less than $0.1 \%$ when the bacteria were challenged at $\mathrm{pH} 3.0$ for $2 \mathrm{~h}$ (Fig. 1). These data do not correlate with a report that $3 \%$ of $Y$. pseudotuberculosis strain 32777 survived when challenged at $\mathrm{pH} 3.0$ for $2 \mathrm{~h}$ (Flamez et al., 2008). It has been reported that some $Y$. pseudotuberculosis isolates carry non-functional alleles of phoP, which is key for survival in the acidic environment in macrophages (Grabenstein et al., 2004). Whether the difference in acid survival between strains 32777 and YpIII is due to the difference in PhoP function needs to be addressed. Moreover, differences in acid survival among different $S$. enterica strains have also been reported (Berk et al., 2005) and it is therefore entirely possible that different strains of $Y$. pseudotuberculosis exhibit different acid survival abilities. Pre-adaptation of YpIII to $\mathrm{pH} 4.5$ for $2 \mathrm{~h}$ greatly enhanced cell survival at $\mathrm{pH} 3.0$ in the presence of urea (Fig. S1), indicating that an adaptive AR also exists in YpIII as reported for S. typhimurium (Bearson et al., 1998) and that acid tolerance at sublethal $\mathrm{pH}$ is a key factor for survival of YpIII at extremely acidic $\mathrm{pH}$. The mechanism by which YpIII withstands extreme acidic stress in vivo is currently under investigation.

The two-component regulator $\mathrm{OmpR}$ has long been considered a global regulator, but the majority of the data concerning OmpR-associated regulation concerns virulence factors and outer-membrane proteins (Brzostek et al., 2007; Yoshida et al., 2006). Although OmpR is known to participate in acid responses in $S$. enterica and $Y$. pseudotuberculosis (Bang et al., 2000; Flamez et al., 2008), the mechanisms behind OmpR-mediated acid survival were not clear. In the present study, we used proteomics analysis to scan targets regulated by OmpR in the acid response and showed that the expression of two urease components, ure $C$ and ure $G$, was increased in the parent YpIII strain at $\mathrm{pH} 4.5$ and downregulated in the $\Delta o m p R$ strain (Fig. 2). Our data strongly suggest that urease, which has been reported to be related to resistance to gastrointestinal stress in several bacteria in the presence of urea (Bandara et al., 2007; Maroncle et al., 2006), is regulated by OmpR during acid survival in YpIII. Studies with other bacterial species have shown that urease expression is activated by H-NS, UreR, NikR and ArsR (Coker et al., 2000; Dattelbaum et al., 2003; Delany et al., 2005; Pflock et al., 2005; Pflock et al., 2006a), but to our knowledge OmpR-mediated urease expression has not been reported previously.

Upon fusing each of the genes in the urease cluster to lac $Z$ we found that OmpR plays a positive regulatory role (Fig. 4), although how OmpR functions in this regulatory process was unclear. Urease is a multimer that contains two or three subunit complexes and several accessory proteins (De Koning-Ward et al., 1994). Earlier studies on ureasemediated acid survival focused on mutation of the whole cluster (De Koning-Ward \& Robins-Browne, 1995) rather than individual component genes, although Northern blot analysis highlighted five transcriptional units, ureABI, ureAB, ureIE', ureI and ure' $F G H$, in $H$. pylori (Akada et 
al., 2000). Our study indicates that there are three transcriptional units (ureABC, ureEF and ureGD) in the YpIII urease cluster and that OmpR binds to the region presumed to be the promoter region upstream of each transcriptional unit (Fig. 6). Upon comparing the interaction of OmpR and urease promoters in the presence and absence of acetyl phosphate, we observed that there was a weaker interaction when OmpR was not phosphorylated (Fig. S2), which suggests that the regulation of urease expression by OmpR is not only direct but also enhanced by OmpR phosphorylation. These data are consistent with a report showing that the regulatory link between OmpR and outer-membrane proteins is enhanced by OmpR phosphorylation (Yoshida et al., 2006). It is noteworthy that the regulation of urease expression by $\mathrm{OmpR}$ was enhanced at acidic pH (Fig. 4b), although there were no differences in expression of OmpR in YpIII between neutral and acidic $\mathrm{pH}$ as determined by $2 \mathrm{D}$-gel or lac $\mathrm{Z}$ fusion analyses (data not shown). These data lead us to speculate that either (i) the phosphorylation of OmpR is promoted by acid, more OmpR thereby binding to urease promoter regions to activate the expression of urease genes at acidic $\mathrm{pH}$ than at neutral $\mathrm{pH}$, or (ii) an acid-induced protein mediates the regulation of urease expression by OmpR, whereby at neutral $\mathrm{pH}$ the absence of mediated protein leads to low expression of urease genes. The detailed mechanism is still largely unknown and needs to be further investigated.

The roles of urease and OmpR in acid survival in YpIII are complicated. Besides OmpR, other regulators also participate in controlling urease expression since urease activity in $\Delta o m p R$ at $\mathrm{pH} 5.0$ and 5.5 was higher than at $\mathrm{pH} 7.0$ (Fig. 3b) and many of the urease gene fusions (most notably ureB-lacZ) are acid-inducible even in the absence of OmpR (Fig. 4b). Moreover, fusions with genes in the same transcriptional unit showed different $\beta$-galactosidase activities. For example, ureD was transcribed together with ureG (Fig. 5), but the expression of ureD was lower than that of ureG (Fig. 4). This suggests that some posttranscriptional regulation of urease production occurs during acid survival. A urease mutant $(\Delta u r e C)$ also exhibited decreased acid survival compared to YpIII in YLB in the absence of added urea (Fig. 3a). To eliminate the effect of low-level urea production from bacterial nitrogen metabolism (Stingl \& De Reuse, 2005), which may affect acid survival, we compared the survival of YpIII in defined M9 medium (without tryptone, yeast extract or other potential urea-containing materials) at $\mathrm{pH} 4.5$; we found no obvious difference in cell survival rates between YpIII and $\Delta u r e C$ (data not shown). This strongly suggests that the role of urease in acid survival is also ureadependent. It is also interesting to note that even without adding urea to the culture medium the acid survival of $\Delta o m p R$ was decreased and was lower than that of $\Delta u r e C$ (Fig. 3a). These results indicate that the role of OmpR in the acid response is multi-faceted; this is also supported by our 2D-gel analyses, where we see several other OmpR- associated proteins which could be related to the acid response (Table S2). Previous studies have shown that the OmpR-regulated porin proteins $\mathrm{OmpC}$ and $\mathrm{OmpF}$ were repressed by acid in E. coli O157:H 7 (Allen et al., 2008) and induced by the acid response regulator CadC in $S$. enterica (Lee et al., 2007). However, our 2D-gel analysis revealed that $\operatorname{ompC}$ and $o m p F$ expression was similar between neutral and acidic $\mathrm{pH}$ in YpIII (data not shown), which indicates that the relationship between these two proteins and $\mathrm{OmpR}$ requires further investigation.

\section{ACKNOWLEDGEMENTS}

This work was supported by the Knowledge Innovation Program of the Chinese Academy of Sciences (KJCW2-YW-W13-01). We thank Dr S. Rayner for helpful comments and suggestions. We also thank Professor L. Wang and the Proteomic Mass Spectrometry Laboratory of TEDA College, Nankai University, for excellent technical support in the 2D-gel and MALDI-TOF MS analyses.

\section{REFERENCES}

Akada, J. K., Shirai, M., Takeuchi, H., Tsuda, M. \& Nakazawa, T. (2000). Identification of the urease operon in Helicobacter pylori and its control by mRNA decay in response to $\mathrm{pH}$. Mol Microbiol 36, 1071-1084.

Allen, K. J., Lepp, D., McKellar, R. C. \& Griffiths, M. W. (2008). Examination of stress and virulence gene expression in Escherichia coli O157: H7 using targeted microarray analysis. Foodborne Pathog Dis 5, 437-447.

Atkinson, S., Throup, J. P., Stewart, G. S. \& Williams, P. (1999). A hierarchical quorum-sensing system in Yersinia pseudotuberculosis is involved in the regulation of motility and clumping. Mol Microbiol 33, 1267-1277.

Bandara, A. B., Contreras, A., Contreras-Rodriguez, A., Martins, A. M., Dobrean, V., Poff-Reichow, S., Rajasekaran, P., Sriranganathan, N., Schurig, G. G. \& Boyle, S. M. (2007). Brucella suis urease encoded by ure1 but not ure2 is necessary for intestinal infection of BALB/c mice. BMC Microbiol 7, 57.

Bang, I. S., Kim, B. H., Foster, J. W. \& Park, Y. K. (2000). OmpR regulates the stationary-phase acid tolerance response of Salmonella enterica serovar typhimurium. J Bacteriol 182, 2245-2252.

Bearson, S., Bearson, B. \& Foster, J. W. (1997). Acid stress responses in enterobacteria. FEMS Microbiol Lett 147, 173-180.

Bearson, B. L., Wilson, L. \& Foster, J. W. (1998). A low pH-inducible, PhoPQ-dependent acid tolerance response protects Salmonella typhimurium against inorganic acid stress. J Bacteriol 180, 2409-2417.

Berk, P. A., Jonge, R., Zwietering, M. H., Abee, T. \& Kieboom, J. (2005). Acid resistance variability among isolates of Salmonella enterica serovar Typhimurium DT104. J Appl Microbiol 99, 859-866.

Blankenhorn, D., Phillips, J. \& Slonczewski, J. L. (1999). Acid- and base-induced proteins during aerobic and anaerobic growth of Escherichia coli revealed by two-dimensional gel electrophoresis. J Bacteriol 181, 2209-2216.

Boot, I. R., Cash, P. \& O'Byrne, C. (2002). Sensing and adapting to acid stress. Antonie Van Leeuwenhoek 81, 33-42.

Bradford, M. M. (1976). A rapid and sensitive method for the quantitation of microgram quantities of protein utilizing the principle of protein-dye binding. Anal Biochem 72, 248-254. 
Brzostek, K., Brzostkowska, M., Bukowska, I., Karwicka, E. \& Raczkowska, A. (2007). OmpR negatively regulates expression of invasin in Yersinia enterocolitica. Microbiology 153, 2416-2425.

Castanie-Cornet, M. P., Penfound, T. A., Smith, D., Elliott, J. F. \& Foster, J. W. (1999). Control of acid resistance in Escherichia coli. J Bacteriol 181, 3525-3535.

Castillo, A., Lucia, L. M., Goodson, K. J., Savell, J. W. \& Acuff, G. R. (1999). Decontamination of beef carcass surface tissue by steam vacuuming alone and combined with hot water and lactic acid sprays. J Food Prot 62, 146-151.

Coker, C., Bakare, O. O. \& Mobley, H. L. (2000). H-NS is a repressor of the Proteus mirabilis urease transcriptional activator gene ureR. J Bacteriol 182, 2649-2653.

Dattelbaum, J. D., Lockatell, C. V., Johnson, D. E. \& Mobley, H. L. (2003). UreR, the transcriptional activator of the Proteus mirabilis urease gene cluster, is required for urease activity and virulence in experimental urinary tract infections. Infect Immun 71, 1026-1030.

De Koning-Ward, T. F. \& Robins-Browne, R. M. (1995). Contribution of urease to acid tolerance in Yersinia enterocolitica. Infect Immun 63, 3790-3795.

De Koning-Ward, T. F., Ward, A. C. \& Robins-Browne, R. M. (1994). Characterisation of the urease-encoding gene complex of Yersinia enterocolitica. Gene 145, 25-32.

Delany, I., leva, R., Soragni, A., Hilleringmann, M., Rappuoli, R. \& Scarlato, V. (2005). In vitro analysis of protein-operator interactions of the NikR and Fur metal-responsive regulators of coregulated genes in Helicobacter pylori. J Bacteriol 187, 7703-7715.

Flamez, C., Ricard, I., Arafah, S., Simonet, M. \& Marceau, M. (2008). Phenotypic analysis of Yersinia pseudotuberculosis 32777 response regulator mutants: new insights into two-component system regulon plasticity in bacteria. Int J Med Microbiol 298, 193-207.

Foster, J. W. (2004). Escherichia coli acid resistance: tales of an amateur acidophile. Nat Rev Microbiol 2, 898-907.

Giannella, R. A., Broitman, S. A. \& Zamcheck, N. (1972). Gastric acid barrier to ingested microorganisms in man: studies in vivo and in vitro. Gut 13, 251-256.

Grabenstein, J. P., Marceau, M., Pujol, C., Simonet, M. \& Bliska, J. B. (2004). The response regulator PhoP of Yersinia pseudotuberculosis is important for replication in macrophages and for virulence. Infect Immun 72, 4973-4984.

Heuveling, J., Possling, A. \& Hengge, R. (2008). A role for Lon protease in the control of the acid resistance genes of Escherichia coli. Mol Microbiol 69, 534-547.

Huang, Y. Y., Deng, J. Y., Gu, J., Zhang, Z. P., Maxwell, A., Bi, L. J., Chen, Y. Y., Zhou, Y. F., Yu, Z. N. \& Zhang, X. E. (2006). The key DNA-binding residues in the C-terminal domain of Mycobacterium tuberculosis DNA gyrase A subunit (GyrA). Nucleic Acids Res 34, 5650-5659.

Karimova, G., Pidoux, J., Ullmann, A. \& Ladant, D. (1998). A bacterial two-hybrid system based on a reconstituted signal transduction pathway. Proc Natl Acad Sci U S A 95, 5752-5756.

Lee, I. S., Slonczewski, J. L. \& Foster, J. W. (1994). A low-pHinducible, stationary-phase acid tolerance response in Salmonella typhimurium. J Bacteriol 176, 1422-1426.

Lee, Y. H., Kim, B. H., Kim, J. H., Yoon, W. S., Bang, S. H. \& Park, Y. K. (2007). CadC has a global translational effect during acid adaptation in Salmonella enterica serovar Typhimurium. J Bacteriol 189, 24172425.

Lennox, E. S. (1955). Transduction of linked genetic characters of the host by bacteriophage P1. Virology 1, 190-206.
Leyer, G. J., Wang, L. L. \& Johnson, E. A. (1995). Acid adaptation of Escherichia coli O157:H7 increases survival in acidic foods. Appl Environ Microbiol 61, 3752-3755.

Lin, J., Lee, I. S., Frey, J., Slonczewski, J. L. \& Foster, J. W. (1995). Comparative analysis of extreme acid survival in Salmonella typhimurium, Shigella flexneri, and Escherichia coli. J Bacteriol 177, 4097-4104.

Maroncle, N., Rich, C. \& Forestier, C. (2006). The role of Klebsiella pneumoniae urease in intestinal colonization and resistance to gastrointestinal stress. Res Microbiol 157, 184-193.

Marshall, B. J., Barrett, L. J., Prakash, C., McCallum, R. W. \& Guerrant, R. L. (1990). Urea protects Helicobacter (Campylobacter) pylori from the bactericidal effect of acid. Gastroenterology 99, 697-702.

Masuda, N. \& Church, G. M. (2003). Regulatory network of acid resistance genes in Escherichia coli. Mol Microbiol 48, 699-712.

Miller, J. H. (1992). A Short Course in Bacterial Genetics: a Laboratory Manual and Handbook for Escherichia coli and Related Bacteria. Cold Spring Harbor, NY: Cold Spring Harbor Laboratory Press.

Mujacic, M. \& Baneyx, F. (2007). Chaperone Hsp31 contributes to acid resistance in stationary-phase Escherichia coli. Appl Environ Microbiol 73, 1014-1018.

Nagano, T., Kiyohara, T., Suzuki, K., Tsubokura, M. \& Otsuki, K. (1997). Identification of pathogenic strains within serogroups of Yersinia pseudotuberculosis and the presence of non-pathogenic strains isolated from animals and the environment. J Vet Med Sci 59, 153-158.

O'Toole, R., Milton, D. L. \& Wolf-Watz, H. (1996). Chemotactic motility is required for invasion of the host by the fish pathogen Vibrio anguillarum. Mol Microbiol 19, 625-637.

Pflock, M., Kennard, S., Delany, I., Scarlato, V. \& Beier, D. (2005). Acid-induced activation of the urease promoters is mediated directly by the ArsRS two-component system of Helicobacter pylori. Infect Immun 73, 6437-6445.

Pflock, M., Finsterer, N., Joseph, B., Mollenkopf, H., Meyer, T. F. \& Beier, D. (2006a). Characterization of the ArsRS regulon of Helicobacter pylori, involved in acid adaptation. J Bacteriol 188, 3449-3462.

Pflock, M., Kennard, S., Finsterer, N. \& Beier, D. (2006b). Acidresponsive gene regulation in the human pathogen Helicobacter pylori. J Biotechnol 126, 52-60.

Richard, H. T. \& Foster, J. W. (2003). Acid resistance in Escherichia coli. Adv Appl Microbiol 52, 167-186.

Rose, R. E. (1988). The nucleotide sequence of pACYC184. Nucleic Acids Res 16, 355.

Rosqvist, R., Skurnik, M. \& Wolf-Watz, H. (1988). Increased virulence of Yersinia pseudotuberculosis by two independent mutations. Nature 334, 522-524.

Ruiz, C., McMurry, L. M. \& Levy, S. B. (2008). Role of the multidrug resistance regulator MarA in global regulation of the $h d e A B$ acid resistance operon in Escherichia coli. J Bacteriol 190, 1290-1297.

Sayed, A. K., Odom, C. \& Foster, J. W. (2007). The Escherichia coli AraC-family regulators GadX and GadW activate gadE, the central activator of glutamate-dependent acid resistance. Microbiology 153, 2584-2592.

Simon, R., Priefer, U. \& Pühler, A. (1983). A broad host range mobilization system for in vivo genetic engineering: transposon mutagenesis in gram negative bacteria. Biotechnology 1, 784-791.

Stingl, K. \& De Reuse, H. (2005). Staying alive overdosed: how does Helicobacter pylori control urease activity? Int J Med Microbiol 295, 307-315.

Takada, A., Umitsuki, G., Nagai, K. \& Wachi, M. (2007). RNase $\mathrm{E}$ is required for induction of the glutamate-dependent acid 
resistance system in Escherichia coli. Biosci Biotechnol Biochem 71, 158-164.

Tramonti, A., De Canio, M., Delany, I., Scarlato, V. \& De Biase, D. (2006). Mechanisms of transcription activation exerted by GadX and GadW at the $\operatorname{gadA}$ and $\mathrm{gadBC}$ gene promoters of the glutamate-based acid resistance system in Escherichia coli. J Bacteriol 188, 8118-8127.

Tucker, D. L., Tucker, N. \& Conway, T. (2002). Gene expression profiling of the $\mathrm{pH}$ response in Escherichia coli. J Bacteriol 184, 6551-6558.
Yoshida, T., Qin, L., Egger, L. A. \& Inouye, M. (2006). Transcription regulation of $o m p F$ and $o m p C$ by a single transcription factor, OmpR. J Biol Chem 281, 17114-17123.

Young, G. M., Amid, D. \& Miller, V. L. (1996). A bifunctional urease enhances survival of pathogenic Yersinia enterocolitica and Morganella morganii at low pH. J Bacteriol 178, 6487-6495.

Edited by: R. J. Maier 